\title{
Infecção disseminada por Chlorella sp. em um ovino
}

\author{
Disseminated infection by Chlorella sp. in a sheep \\ Everton Ferreira Lima ${ }^{\mathrm{I}}$ Lisanka Ângelo Maia ${ }^{\mathrm{I}}$ Eduardo Melo de Nascimento ${ }^{\mathrm{I}}$
Antônio Flávio Medeiros Dantas ${ }^{\mathrm{I}}$ Franklin Riet-Correa $^{\mathrm{I}^{*}}$
}

RESUMO

Descreve-se um caso de infecção disseminada por Chlorella sp. em um ovino, na região semiárida da Paraíba, Brasil. O animal apresentou emagrecimento e aumento de volume abdominal há um mês. Na necropsia, foram observados nódulos esverdeados em fígado, pulmões, intestino e linfonodos. Histologicamente, os nódulos correspondiam a piogranulomas com miríades de algas intralesionais. Provavelmente, a infecção tenha ocorrido em consequência do consumo de água estagnada ou capim que tinha sido cortado em uma área irrigada, que são condições frequentes no período da seca na região semiárida.

Palavras-chave: alga verde, Chlorella sp., doenças de ovinos.

\section{ABSTRACT}

A case of disseminated infection by Chlorella sp. is reported in a sheep in semiarid region of Paraíba, northeastern Brazil. The animal showed weight loss and abdominal distension. At necropsy greenish nodules were observed in liver, lung, intestine and lymph nodes. Histologically the nodules corresponded to pyogranulomas with myriad of intralesional algae. Probably the infection occurred as a result of the consumption of stagnant water or grass which had been cut in an irrigated area, conditions that are common in the dry season in the semiarid region.

Key words: green alga, Chlorella sp., diseases of sheep.

Chlorella spp. é uma alga verde unicelular, que contém clorofila, pertencente ao filo Chlorophita, classe Trebouxiophyceae, ordem Chlorellales e família Chlorellaceae (LUO et al., 2010). Esses microrganismos devem ser diferenciados do gênero Prototheca, que também são organismos unicelulares, sem clorofila, pertencentes ao mesmo grupo filogenético da Chlorella. Ao contrário da Prototheca, membros do gênero Chlorella contêm grânulos citoplasmáticos, que representam amido e cloroplastos, fortemente corados pelo Ácido Periódico Schiff (PAS) (HAENICHEN et al., 2002).

As infecções causadas por algas unicelulares são raras, mas geralmente têm sido devidas a Prototheca spp. (KRCMÉRY JR., 2000; QUIGLEY et al., 2009). No Brasil, foi relatada a infecção por Prototheca wickerhami em caprinos com lesões cutâneas e nasal na região semiárida do Nordeste (CAMBOIM et al., 2011), e mastite em bovinos por Prototheca spp. (CORBELLINI et al., 2001), mas não há relatos de infecção por Chlorella spp. em animais domésticos. O objetivo deste trabalho é relatar um caso de infecção disseminada por Chlorella sp. em ovino na região semiárida do Brasil.

A doença ocorreu em um ovino, fêmea, de dois anos de idade, prenhe, atendido no Hospital Veterinário da Universidade Federal de Campina Grande em dezembro de 2012, que há um mês apresentava emagrecimento e aumento de volume abdominal. Na propriedade, localizada no município de Patos, Paraíba, havia 60 ovinos e 10 bovinos, com histórico de intoxicação por Tephrosia cinerea em ovinos. $\mathrm{Na}$ área onde estavam os ovinos, havia poços, lagos e bebedouros com água estagnada e esverdeada. Os animais se alimentavam de capim Echinochloa polystachya cortado e proveniente de área irrigada. No exame clínico, observou-se leve palidez das mucosas, caquexia,

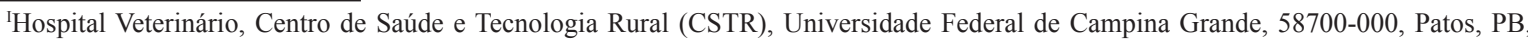
Brasil. E-mail: franklin.riet@pq.cnpq.br. *Autor para correspondência. 
dificuldade de manter-se em estação e ascite. No exame coproparasitológico, havia infecção por Trichostrongyloidea (3.000 OPG). Verificouse aumento da atividade sérica das enzimas

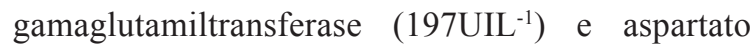
aminotransferase (460UI L ${ }^{-1}$ ) e hipoalbuminemia $\left(0,82 \mathrm{~g} \mathrm{dL}^{-1}\right)$. O eritrograma apresentou-se normal e o leucograma teve eosinofilia $\left(3.836 \mathrm{~mm}^{3}\right)$. Devido à suspeita clínica de intoxicação por $\mathbf{T}$. cinerea e ao quadro clínico desfavorável, o animal foi eutanasiado e necropsiado.

Macroscopicamente, o fígado estava aumentado de tamanho com múltiplos nódulos esverdeados variando de 0,2 a $0,4 \mathrm{~cm}$ de diâmetro, distribuídos por toda superfície capsular e de corte (Figura 1A). A vesícula biliar estava distendida e com parede espessada. Os linfonodos hepáticos, traqueobrônquicos, inguinais e principalmente os mesentéricos estavam aumentados de volume, esverdeados (Figura 1B) e com superfície subcapsular irregular. Ao corte, observou-se superfície difusamente esverdeada e friável, sem distinção da região cortical e medular, às vezes entremeadas por áreas esbranquiçadas, opacas e deprimidas (Figura 1C). Os vasos linfáticos estavam evidentes, distendidos e esverdeados, principalmente no omento, mesentério (Figura 1B) e linfonodos mesentéricos e hepáticos. Na serosa do jejuno e íleo, foi observada área focalmente extensa, contendo múltiplos nódulos esverdeados, variando de 0,3 a $0,5 \mathrm{~cm}$ de diâmetro. A mucosa dessas alças intestinais estava espessada e com múltiplas áreas ulceradas (Figura 1B), mais intensas nas placas de Peyer e na valva íleo-cecal. Nos pulmões, observaram-se raros nódulos esverdeados multifocais, variando de 0,2 a $0,8 \mathrm{~cm}$ de diâmetro na superfície pleural e no parênquima. Não foram observadas lesões macroscópicas em outros órgãos e no feto.

Amostras de órgãos das cavidades abdominal e torácica e sistema nervoso central foram coletadas e fixadas em formol tamponado a $10 \%$, embebidas em parafina, cortadas em $5 \mu \mathrm{m}$ e coradas pela Hematoxilina e Eosina (HE). Fígado e linfonodos foram corados pelas técnicas histoquímicas de Grocott e (PAS).

As lesões microscópicas foram semelhantes nos órgãos afetados e caracterizaram-se por discreta ou acentuada inflamação piogranulomatosa associada a miríades de algas intralesionais compatíveis com Chlorella sp. As algas variaram de redondas a ovais e mediam entre 12 a $60 \mu \mathrm{m}$, apresentando núcleo redondo basofílico e citoplasma eosinofílico a anfofílico, contendo múltiplos grânulos basofílicos, envolto por uma fina parede celular eosinofílica e refrátil (esporângios) (Figura 1D). Os grânulos foram fortemente corados pelo PAS (Figura 1E) e no Grocott houve impregnação de grânulos e parede celular (Figura 1F). Havia raras células grandes (esporângios) preenchidas com 3 a 7 células filhas (esporangiósporos ou endósporos). Também foram observadas algas com parede celular intacta e sem estruturas internas (algas degeneradas). No fígado, havia áreas multifocais a coalescente de necrose contendo miríades de algas intralesionais, associadas a escasso infiltrado inflamatório, composto predominantemente por macrófagos, linfócitos, plasmócitos, neutrófilos, macrófagos epitelioides e células gigantes multinucleadas, algumas contendo algas intracitoplasmáticas, observadas principalmente na região periportal, associada à moderada fibrose (Figura 1E). As algas também foram observadas distendendo os sinusoides e ao redor e na luz de vasos. Nos intestinos, observou-se substituição completa da mucosa por miríades de algas, associada a infiltrado inflamatório piogranulomatoso distendendo a lâmina própria. Em algumas áreas, as lesões se estendiam à submucosa, muscular e serosa. No rúmen, foi observada distensão acentuada da lâmina própria por múltiplos agregados de algas, associadas à discreto infiltrado inflamatório composto por neutrófilos, macrófagos, linfócitos e plasmócitos, e fusão de papilas ruminais. Os agregados se estendiam para a camada muscular externa e localizavam-se entre as fibras musculares. Observou-se também hiperplasia das células epiteliais das papilas ruminais.

Nos linfonodos hepáticos e mesentéricos, havia perda da arquitetura do órgão com substituição total do parênquima por necrose, numerosas algas e discreto infiltrado inflamatório misto. Os poucos folículos linfoides que restaram estavam infiltrados por algas. Observaram-se também nos pulmões áreas multifocais de necrose e algas associadas a discreto infiltrado inflamatório misto nos septos e alvéolos adjacentes. Algas também foram observadas isoladas na luz de capilares alveolares e espessando os septos interalveolares, além de serem encontradas nos glomérulos e no interstício renal e entre as fibras cardíacas, muitas vezes associadas a infiltrado inflamatório linfoplasmocítico.

O diagnóstico de chlorelose disseminada nesse ovino foi realizado com base nos dados epidemiológicos, clínicos e patológicos. A coloração esverdeada dos órgãos afetados, associada à presença de algas intralesionais, contendo grânulos citoplasmáticos PAS positivos, são aspectos importantes para diferenciar Chlorella de outras algas que possuem características morfológicas 


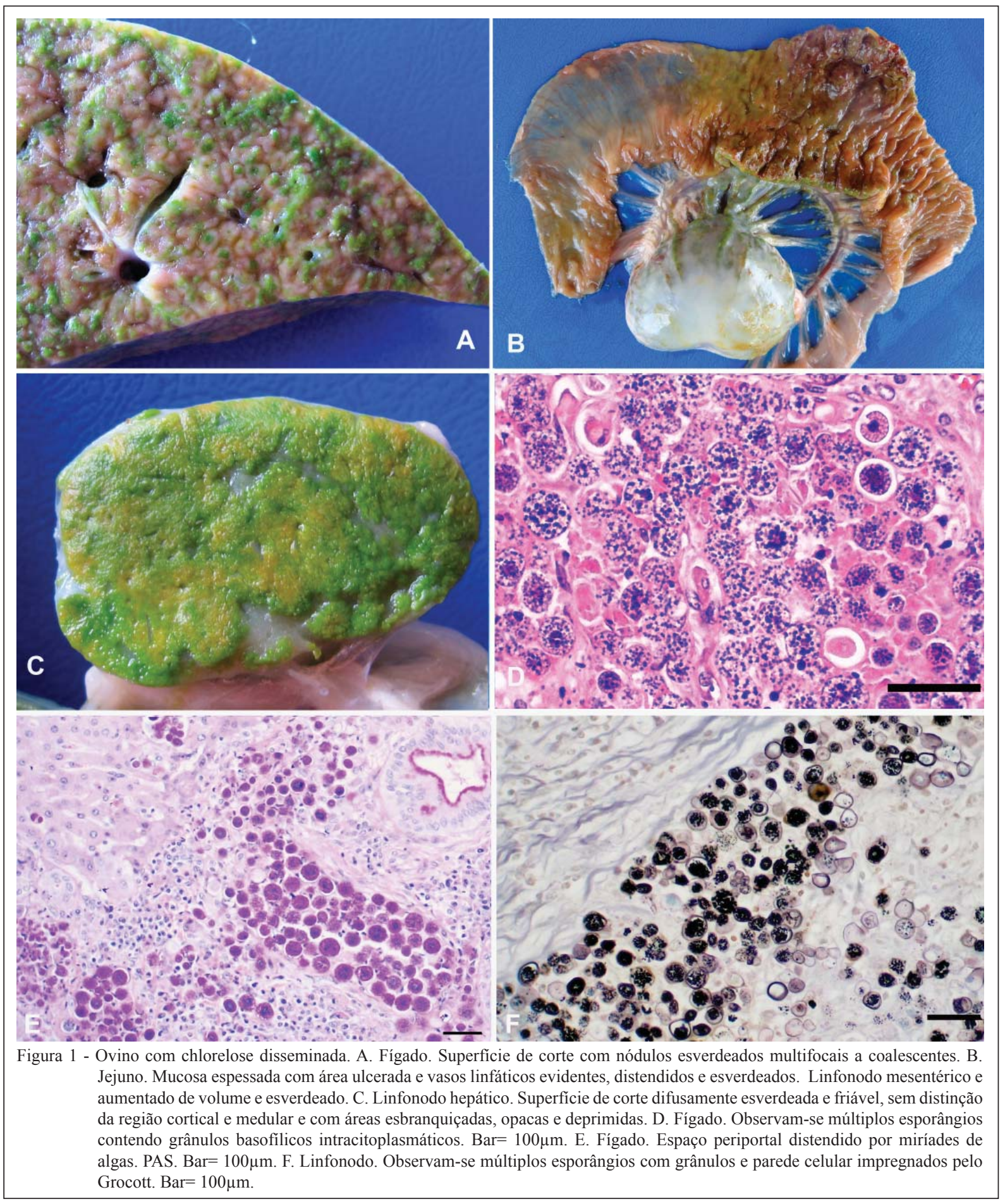

semelhantes, como Prototheca (RAMIREZROMERO et al., 2010). Considerando que Chlorella sp. não cresce em culturas, outras formas de diagnóstico podem ser utilizadas, incluindo a microscopia eletrônica de transmissão e o diagnóstico molecular (HAFNER et al., 2012).
A infecção por Chlorella sp. pode ser localizada ou disseminada. Lesões cutâneas localizadas foram descritas em gazela (HAENICHEN et al., 2002) e humanos (KRCMÉRY JR., 2000), associadas a trauma e águas contaminadas. Lesões localizadas em linfonodos e fígado foram 
observadas em bovinos e em um ovino de abatedouro como achados incidentais sem apresentação clínica (CORDY, 1973; ROGERS et al., 1980). Em dromedário, foi descrita a infecção entérica localizada, associada à diarreia crônica persistente (LE NET et al., 1993). A forma disseminada da infecção foi relatada em um cão (QUIGLEY et al., 2009), ovinos (RAMIREZ-ROMERO et al., 2010) e bovinos (HAFNER et al., 2012). No caso descrito neste trabalho, a presença de microrganismos em vários tecidos caracteriza infecção disseminada por Chlorella sp., possivelmente associada à imunossupressão (LE NET et al., 1993; QUIGLEY et al., 2009), decorrente da gestação, influenciada pelo parasitismo intestinal ou pela escassez de alimentos na região. A localização das lesões sugere que a via de infecção tenha sido o trato digestivo e a presença de algas na luz de vasos sanguíneos e linfáticos indica a posterior disseminação para outros órgãos. Em ovinos, a infecção disseminada geralmente ocorre via trato digestivo, quando os animais ingerem água contaminada e/ou se alimentam de pastagens irrigadas com águas contaminadas por esgotos (RAMIREZROMERO et al., 2010). No presente estudo, acredita-se que a principal fonte de infecção foi a água estagnada e esverdeada de poços e bebedouros. Outra possibilidade é que a infecção tenha ocorrido pela ingestão de capim cortado, proveniente de uma área irrigada próximo a um açude contaminado por esgotos. Essas práticas de manejo são frequentes na região semiárida no período de seca.

Neste caso, as principais alterações clínicas e laboratoriais foram características de insuficiência hepática, sugerindo a necessidade de se realizar o diagnóstico diferencial com as intoxicações por plantas hepatotóxicas, incluindo $\mathbf{T}$. cinerea e Crotalaria retusa, frequentes em ovinos da região.

\section{REFERÊNCIAS}

CAMBOIM, E.K.A. et al. Protothecosis by Prototheca wickerhamii in goats. Mycoses, v.54, p.196-200, 2011. Disponível em: <http://doi/10.1111/j.1439-0507.2010.01864.x>. Acesso em: 6 ago. 2013. doi:10.1111/j.14390507.2010.01864.x.
CORBELlini, L.G. et al. Bovine mastitis due to Prototheca zopfii: clinical, epidemiological and pathological aspects in a Brazilian dairy herd. Tropical Animal Health and Production, v.33, p.463-470, 2001.

CORDY, DR. Chlorellosis in a lamb. Veterinary Pathology, v.10, p.171-176, 1973. Disponível em: <http://dx.doi.org/10. 1177/030098587301000209>. Acesso em: 09 dez. 2012. doi: $10.1177 / 030098587301000209$.

HAENICHEN, T. et al. Cutaneous chlorellosis in a gazelle (Gazella dorcas). Veterinary Pathology, v.39, p.386-389, 2002. Disponível em: <http://dx.doi.org/10.1354/vp.39-3-386>. Acesso em: 19 dez. 2012. doi: 10.1354/vp.39-3-386.

HAFNER, S. et al. Green Algal peritonitis in 2 cows. Veterinary Pathology, v.50, p.256-259, 2012. Disponível em: <http://dx.doi. org/10.1177/0300985812450722>. Acesso em: 15 maio, 2013. doi: $10.1177 / 0300985812450722$.

KRCMÉRY, V. Jr. Systemic chlorellosis, an emerging infection in humans caused by algae. International Journal Antimicrobial Agents, v.15, p.235-237, 2000

LE NET, J.-L. et al. Granulomatous enteritis in a dromedary (Camelus dromedarius) due to green algal infection. Veterinary Pathology, v.30, p.370-373,1993. Disponível em: <http://dx.doi. org/10.1177/030098589303000406>. Acesso em: 19 dez. 2012. doi: $10.1177 / 030098589303000406$.

LUO, W. et al. Generic concept in Chlorella related coccoid green algae (Chlorophyta, Trebouxiophyceae). Plant Biology, v.12, p.545-553, 2010. Disponível em: <http://dx.doi.org/10 $.1111 /$ j.1438-8677.2009.00221.x>. Acesso em: 12 fev. 2013. doi: 10.1111/j.1438-8677.2009.00221.x.

QUIGLEY, R.R. et al. Disseminated chlorellosis in a dog. Veterinary Pathology, v.46, p.439-443, 2009. Disponível em: $<$ http://dx.doi.org/10.1354/vp.08-VP-0142-Q-BC>. Acesso em: 15 maio, 2013. doi: 10.1354/vp.08-VP-0142-Q-BC.

RAMIREZ-ROMERO, R. et al. Chlorella infection in a sheep in Mexico and minireview of published reports from humans and domestic animals. Mycopathologia, v.169, p.461-466, 2010. Disponível em: <http://dx.doi.org/10.1007/s11046-010-9287-4>. Acesso em: 19 dez. 2012. doi: 10.1007/s11046-010-9287-4.

ROGERS, R.J. et al. Lymphadenitis of cattle due to infection with green algae. Journal of Comparative Pathology, v.90, p.19, 1980. Disponível em: <http://doi.0021-9973/80/010001+09 S02.00/0>. Acesso em: 19 dez. 2012. 